\title{
A disseminação de informação científica em escolas de governo como fator de inovação social
}

\section{The dissemination of scientific information in government schools as a factor of social innovation}

\author{
Alessandra de Souza Santos ${ }^{1}$, Frederico Carvalho Figueiredo ${ }^{2}$ \\ 1 Universidade FUMEC, Belo Horizonte, Minas Gerais, Brasil. ORCID: https://orcid.org/0000-0002-6386-4864 \\ 2 Pontifícia Universidade Católica de Minas Gerais, Belo Horizonte, Minas Gerais, Brasil. ORCID: https://orcid.org/0000-0002-9173-9251
}

Autor para correspondência/Mail to: Alessandra de Souza Santos, alessandra@mpmg.mp.br

Recebido/Submitted: 04 de fevereiro de 2019; Aceito/Approved: 31 de março de 2020

Copyright (c) 2020 Santos \& Figueiredo. Todo o conteúdo da Revista (incluindo-se instruções, política editorial e modelos) está sob uma licença Creative Commons Atribuição-NãoComercial-Compartilhalgual 3.0 Não Adaptada. Ao serem publicados por esta Revista, os artigos são de livre uso em ambientes educacionais, de pesquisa e não comerciais, com atribuição de autoria obrigatória. Mais informações em http://revistas.ufpr.br/atoz/about/submissions\#copyrightNotice.

\begin{abstract}
Resumo
Introdução: o desenvolvimento local e a inclusão social são fundamentalmente interligados à disseminação da informação científica como fator de inovação social. Nesse contexto, as Escolas de Governo devem se estruturar como espaços de trocas de conhecimentos críticos das relações de poder subjacentes no acesso ao conhecimento.

Objetivo: objetiva verificar a frequência da ocorrência de periódicos de acesso livre e de repositórios abertos, como instrumentos de disseminação de informação científica em Escolas de Governo do Ministério Público brasileiro, e analisar sua importância na transformação da realidade social sob a ótica da inovação social. Diferentes conceitos de inovação social foram abordados em diálogo com o papel formativo do Estado, por meio de suas Escolas de Governo e seus diferentes instrumentos de disseminação de informação científica.

Metodologia: consiste em estudo exploratório de natureza qualitativa, com coleta de dados por meio de pesquisa documental em repositórios abertos e portais corporativos das Escolas de Governo dos Ministérios Públicos no Brasil. Trata os dados por meio de tabulação da frequência da ocorrência dos instrumentos.

Conclusão: sugere que o número de Escolas de Governo que não possuem instrumentos de disseminação de informação científica aberta ainda é alto. Demonstra a relevância de políticas institucionais que fortaleçam as Escolas dos Ministérios Públicos, principalmente aquelas Escolas Institucionais, cujas estruturas administrativas integram as Instituições. Importante também a efetividade da busca dos repositórios e revistas que nem sempre são amigáveis com os usuários.
\end{abstract}

Palavras-chave: Inovação Social; Disseminação de Informação; Escola de Governo.

\begin{abstract}
Introduction: local development and social inclusion are fundamentally linked to the dissemination of scientific information as a factor of social innovation In this context Schools of Government must be structured as spaces for the exchange of critical knowledge of the underlying power relations in access to knowledge.

Objective: it aims to verify the frequency of occurrence of open access journals and open repositories as tools to disseminate scientific information in government schools of the Brazilian Public Ministry and to analyze their importance in the transformation of social reality for social innovation. Different concepts of social innovation were approached in dialogue with the formative role of the State, through its Schools of Government and its different instruments of dissemination of scientific information.

Method: it consisted of an exploratory study of a qualitative nature, with data collection utilizing documentary research in open repositories and corporate portals of Government Schools of Brazilian Public Ministries and data treatment through tabulation of the frequency of occurrence of the instruments. Conclusions: it suggest that the number of Government Schools that do not have tools to disseminate open scientific information is still high. The study demonstrates the relevance of institutional policies that strengthen the Schools of Public Prosecutions, especially those Institutional Schools, whose administrative structures integrate the Institutions. It is also important to point out the search for the effectiveness of repositories and magazines, which are not always user-friendly.
\end{abstract}

Keywords: Social Innovation; Information Dissemination; School of Government.

\section{INTRODUÇÃO}

As Escolas de Governo, instituições destinadas à formação e ao desenvolvimento de servidores públicos, têm importante papel na transformação da realidade social e na promoção de cidadania, por meio da formação e aperfeiçoamento dos quadros de servidores públicos. Essa temática, dada sua relevância, tem tratamento, inclusive, em nível constitucional. Esse tema é disciplinado na Constituição da República Federativa do Brasil de 1988. (1988), em sua Emenda Constitucional no 19, de 04 de junho de 1998, que dá nova redação ao $\S 2^{\circ}$ do art. 39 da Constituição Federal, que passa a vigorar com a seguinte redação:

Art. $39[\ldots]$ § $2^{\circ}$ A União, os Estados e o Distrito Federal manterão escolas de governo para a formação e o aperfeiçoamento dos servidores públicos, constituindo-se a participação nos cursos um dos requisitos para a promoção na carreira, facultada, para isso, a celebração de convênios ou contratos entre os entes federados. 
O Decreto $n^{\circ} 5.70 \%$, de 23 de fevereiro de 2006 (2006), que institui a Política Nacional de Desenvolvimento de Pessoal, evidencia essa relevância. Segundo a norma, Escolas de Governo podem estar vinculadas direta ou indiretamente à administração pública federal direta, autárquica e fundacional, sendo "financiadas e/ou mantidas por recursos públicos" (Ranzini \& Bryan, 2017, p. 419). Esse decreto explicita que as Escolas de Governo devem contribuir para a identificação das necessidades de capacitação dos órgãos e das entidades, considerando-as na programação de suas atividades de formação, capacitação e treinamento.

Nesse contexto, ressalta-se necessidade de disseminação ampla e livre da informação como fator de promoção de cidadania e inovação social, uma vez que ao garantir o acesso aberto e livre à informação a Escola de Governo cumpre sua função social e institucional de permitir a apropriação da informação em nível local. Ressalte-se também o papel da Escola de Governo como espaço de inclusão social e de acesso, nos termos da Declaração de Salamanca e Linha de Ação sobre Necessidades Educativas Especiais (1994), em face de uma crescente mobilização e cobrança social por qualidade e eficiência por parte da prestação de serviços públicos.

A promoção da inovação social deve ser tratada de forma conjunta com a promoção do desenvolvimento local e da inclusão social e que a disseminação da informação e a inovação social são indissociáveis (Bertin, Leite, \& Pereira, 2009), pois a apropriação da informação presente em acervos é condição para que ocorra a inovação. Sem a difusão, não existe impacto econômico de uma inovação (Bertin et al., 2009). Guédon (2010), enfatiza o valor simbólico do acesso aberto ao conhecimento, abordando as relações de poder resultantes das distintas formas de acesso a esse determinado conhecimento. Adicionalmente, o movimento para o acesso livre ao conhecimento científico surge, então, "como o fato mais interessante e talvez importante de nossa época no que se refere à comunicação científica" (Mueller, 2006, p. 27). Sob essa ótica, os periódicos de acesso livre e os repositórios abertos se destacam no processo de disseminação de documentação científica (Guimarães, Silva, \& Borges, 2015; Shintaku \& Vidotti, 2016). Para fins de definição da conceituação, utiliza-se o termo "acesso aberto" para designar a opção de uso do conteúdo, respeitando-se direitos autorais e o termo "acesso livre" para designar o modelo de negócio de periódico científico gratuito (Bayley, 2003 apud (Guédon, 2010).

Acrescente-se que se tem por paradigma a Escola Nacional de Administração Pública (ENAP), cujo repositório institucional tem como objetivos organizar e disponibilizar a sua produção técnica e científica; aumentar a visibilidade e o acesso à pesquisa técnica e científica da ENAP, em acesso aberto, em conformidade com a Lei $n^{\circ}$. 12.527, de 18 de novembro de 2011 (2011); aumentar a interoperabilidade de toda a produção da ENAP em rede; preservar e armazenar a memória institucional da ENAP; e disponibilizar recursos de aprendizagem produzidos pela ENAP ou no âmbito de suas parcerias ((Muller \& Oliveira, 2015). A Revista do Serviço Público (RSP) é o periódico científico da ENAP de acesso livre e utiliza o gerenciamento pelo Sistema Eletrônico de Editoração de Revistas (SEER). Segundo a (Ranzini \& Bryan, 2014), a missão da RSP é "disseminar conhecimentos e estimular a reflexão e o debate, apoiando o desenvolvimento dos servidores, o seu compromisso com a cidadania e a consolidação de uma comunidade de praticantes, especialistas e interessados nos temas de políticas públicas e gestão governamental". A mesma norma legal estabelece que a RSP objetiva promover, incentivar e abrigar a pesquisa e a divulgação de trabalhos científicos relevantes, incentivar a produção de conhecimento para a formulação e implementação de políticas, governança e gestão e disseminar boas práticas.

O presente trabalho teve por objetivo geral verificar a frequência da ocorrência de periódicos de acesso livre e de repositórios abertos em Escolas de Governo do Ministério Público brasileiro. Objetivou-se, em específico, analisar a importância do papel da disseminação da informação para a promoção da inovação social; apresentar diferentes modelos de Escolas de Governo e; verificar a frequência que periódicos de acesso livre e os repositórios abertos aparecem como instrumentos de disseminação de informação científica aberta em Escolas de Governo dos Ministérios Públicos no Brasil.

O método utilizado na pesquisa foi exploratório e a pesquisa teve natureza qualitativa. A coleta de dados foi feita por meio de pesquisa documental, com pesquisa em repositórios abertos e portais corporativos extranet das Escolas de Governo dos Ministérios Públicos no Brasil. O tratamento dos dados foi realizado por meio de tabulação da frequência de ocorrência dos instrumentos de disseminação aberta da informação.

No presente trabalho, optou-se por focar nos periódicos de acesso livre e os repositórios abertos como instrumentos abertos de disseminação de informação científica potencialmente em uso nas Escolas de Governo dos Ministérios Públicos no Brasil, para se abordar a inovação social em diálogo com o papel formativo do Estado em busca de resultados de transformação social. Essa escolha se justifica em razão de essas escolas participarem do Colégio de Diretores de Escolas dos Ministérios Públicos do Brasil (CDEMP), cujo objetivo é estabelecer maior intercâmbio científico entre os Ministérios Públicos de todo o Brasil; da Carta de Brasília, de 22 de setembro de 2016 (2016), um acordo de resultados firmado entre a Corregedoria Nacional e as Corregedorias das unidades do Ministério Público, que explicita premissas para a concretização do compromisso institucional de gestão e atuação resolutiva, prevendo diretrizes estruturantes do Ministério Público; e também da uniformização de estrutura e atuação pretendida com a expedição da Recomendação de Caráter Geral CN-CNMP n. ${ }^{\circ}$ 2, de 4 de julho de 2017 (2017), pelo Conselho Nacional do Ministério Público (CNMP) e a Corregedoria Nacional do Ministério Público (CN). Essa recomendação estabelece diretrizes para a estruturação e a atuação das Escolas Institucionais do Ministério Público brasileiro e fixa orientações para a interação entre as Escolas e outros órgãos 
da administração, notadamente quanto ao alinhamento ao planejamento estratégico institucional.

\section{DESENVOLVIMENTO}

\section{Inovação Social}

O conceito de inovação social é polissêmico, segundo Carbonell (2002), e representa um conjunto de intervenções sistematizadas, que podem ser processos, produtos, decisões, etc., e com um certo grau de intencionalidade que geram modificações nas atitudes, ideias, culturas. Para o autor, esse conceito é condicionado à ideologia, às relações de poder, às conjunturas sociais, políticas e econômicas. Ademais, segundo Carbonell (2002), a mudança é como um quebra-cabeça acabado e quando falta uma peça, existe um impacto negativo no conjunto e por isso a inovação tem que ser abordada de modo sistêmico.

Para Diogo e Guerra (2003), a inovação social representa uma utopia renovada que serve tanto como ponto de partida como de chegada para se promover a justiça no espaço-tempo, isto é no contexto social, histórico, econômico e espacial. A inovação social ocorre por meio de promoção de cidadania e inclusão social que, por sua vez resultam do trabalho em rede; da atuação pró-ativa de todos os agentes envolvidos; da sensibilização e que garante a participação e a duradoura mudança de mentalidade. Essas mudanças de modelos mentais são importantes, pois a inovação social "floresce nas relações que se criam nas comunidades, nas regiões e nos estados, com o objetivo último de ampliar as liberdades individuais dos indivíduos, quer em termos de recursos, quer de oportunidades" (Diogo \& Guerra, 2003, p. 158). Para os autores, a inovação social é uma proposta contra-hegemônica pois trata-se de "uma via efetiva e criativa para a resolução de problemas sociais, no sentido de melhorar o bem-estar social e promover o desenvolvimento" (Diogo \& Guerra, 2003, p. 142) e pode ter sua significância mensurada pela escala que atinge (número de pessoas, área geográfica), pelo seu alcance (capacidade de integrar diversos problemas sociais) e pela ressonância que provoca (intensidade com que se integra nos modelos mentais das pessoas) (Nilsson, 2003, apud (Diogo \& Guerra, 2003). Segundo os autores, a inovação social gera uma mudança que restaura a capacidade de resiliência dos sistemas, a partir da capacitação das populações, potenciando o seu capital humano e social.

Para Bignetti (2011), a inovação social é definida como o resultado do conhecimento aplicado a necessidades sociais por meio da participação e da cooperação dos atores envolvidos, gerando soluções novas e duradouras para grupos sociais, comunidades ou para a sociedade em geral.

Baumgarten (2017) define inovação social, como sendo a pesquisa de produtos e processos que se destinam ao atendimento de necessidades sociais (educação, saúde). As concepções avançam, portanto, no sentido de ampliar a concepção de inovação social, ao incluir ao conceito de inovação de produtos, processos, a própria criação do conhecimento e a sua disseminação e apropriação pela comunidade, que participa do processo e constrói socialmente as soluções.

Há autores que avançaram no sentido de ampliar a conceituação de inovação social, acrescentando como passível de inovação não somente produtos, processos, mas também a própria criação do conhecimento e a sua disseminação e apropriação pela comunidade, que participa do processo e constrói socialmente as soluções. Dagnino e Gomes (2000 apud (Dagnino, Brandão, \& Novaes, 2004, p. 21) definem inovação social como o "conhecimento - intangível ou incorporado a pessoas ou equipamentos, tácito ou codificado - que tem por objetivo o aumento da efetividade dos processos, serviços e produtos relacionados à satisfação das necessidades sociais".

Para Lacerda e Ferrarini (2013), a inovação social pressupõe (i) a abertura de espaços de gestão em que se criem instrumentos para uma esfera pública de cogestão dos recursos públicos; (ii) a ênfase no compartilhamento entre empresas, Estado e sociedade civil no planejamento, intervenção, apropriação dos resultados, difusão e avaliação do processo de inovação, respeitando as características e necessidades locais e; (iii) a primazia dos atores sociais no processo de gestão social.

\section{Disseminação da informação como inovação social}

Com a atual economia do conhecimento, a estrutura de produção, apropriação e disseminação do conhecimento torna dominantes os novos fluxos e padrões de inserção do conhecimento nos processos de produção e de serviços contemporâneos, em razão da importância do conhecimento intangível em todos os setores da economia (Arbix, 2010). Bertin et al. (2009) corroboram essa afirmativa e enfatizam que a disseminação da informação e a inovação social são indissociáveis. Para os autores, portanto, não importa se a ideia é nova ou não, mas sim a apropriação que os sujeitos de uma comunidade fazem dessa ideia, pois estoques de informação e acervos de conhecimentos por si só não criam qualquer conhecimento e sem a difusão, não existe impacto econômico de uma inovação. No entanto, nessa concepção, a promoção da inovação social, deve ser tratada de forma conjunta com a promoção do desenvolvimento local e da inclusão social. Para Bertin et al. (2009), isso gera implicações para as instituições públicas e eles lançam o questionamento sobre o papel do Estado nas políticas de pesquisa, desenvolvimento e inovação, uma vez que a informação em ciência e tecnologia sejam capazes de provocar inovação também em âmbito social. 
Para Lacerda e Ferrarini (2013), o Estado é um elemento de destaque no tocante ao fortalecimento de sua função intermediadora da participação, garantindo espaços democráticos de formação, discussão e deliberação guiadas pelo princípio da justiça social. Na perspectiva dos autores, o Estado se caracteriza como Estado-facilitador dos processos sociais. As Escolas de Governo, em uma análise mais detida, seriam locais de participação e diálogos múltiplos, em razão da missão de formação dos quadros de servidores públicos.

\section{Principais instrumentos de disseminação da informação científica}

Ao abordarmos especificamente os diversos instrumentos de disseminação de informação científica passível de ser utilizada no âmbito de Escolas de Governo, ressalte-se a Declaração de Budapeste. (2002) ("Budapest Open Access Initiative" - BOAI) que desencadeou o Movimento de Acesso Livre à informação científica (Guimarães et al., 2015) e a Declaração de Berlin Sobre o Acesso Aberto ao Conhecimento em Ciê ncia e Humanidade. (2003) Sobre o Acesso Aberto ao Conhecimento em Ciências e Humanidade que amplia as fronteiras do movimento de livre acesso ao explicitar a conceituação de acesso livre, incluindo "resultados de pesquisas científicas originais, dados brutos [dados não processados] e metadados, fontes originais, representações digitais de materiais pictóricos e gráficos além de material acadêmico multimídia" (Sayão \& Sales, 2014, p. 77). No contexto de acesso livre à pesquisa, destacam-se os periódicos de acesso aberto e os repositórios no processo de disseminação de documentação científica ((Guimarães et al., 2015; Shintaku \& Vidotti, 2016).

Segundo Costa (2008, p. 229), as políticas nacionais de acesso aberto adotadas pelo Instituto Brasileiro de Informação em Ciência e Tecnologia (IBICT) "enfocam tanto os periódicos eletrônicos quanto os repositórios institucionais e fundamentam-se na questão da interoperabilidade e na questão da ausência de barreiras de preço e de permissão de uso".

Os repositórios são espaços virtuais no qual têm sido alocadas fontes digitalizadas dos projetos coletivos de pesquisa (Costa \& Valente, 2015) e constituem-se em acervos de conhecimento, podendo ser usados, reusados e compartilhados (Sayão \& Sales, 2014). Para Muller e Oliveira (2015), vários são os benefícios com a criação de um repositório institucional, uma vez que estes organizam e ampliam a visibilidade da produção intelectual da instituição, tornando-a mais fácil de ser encontrada e reutilizada; oferecem um espaço de armazenamento digital permanente dos trabalhos e pesquisas; oferecem mecanismos para se acompanhar indicadores de impacto da produção intelectual da instituição; oferecem flexibilidade de pesquisa e integração, por meio da interoperabilidade com sistemas de buscas (Google, Google Scholar, Yahoo) e outras bases de dados estimulando a disseminação das informações. No âmbito do serviço público, os repositórios podem ainda auxiliar gestores em seus processos decisórios e planos estratégicos; além de fomentarem a colaboração entre pesquisadores, facilitando a livre troca de informação científica (Muller \& Oliveira, 2015). No Brasil, as políticas do IBICT a respeito de repositórios, consistem em incentivar, instrumentar e capacitar as organizações no uso do DSpace ou do E-prints, plataformas desenvolvidas e distribuídas pelo Massachusetts Institute of Technology (MIT) e University of Southampton, respectivamente (Costa, 2008).

Os periódicos científicos são revistas indexadas e arbitradas (normalmente com sistema de double blind peer review) e constituem-se em "canais preferenciais para a certificação do conhecimento científico e para a comunicação autorizada da ciência" (Mueller, 2006, p. 27). No que concerne aos periódicos no Brasil, Vanti (2010) afirma que tem havido políticas de incentivo à editoração de periódicos eletrônicos por agências de fomento à pesquisa. Isso se deve por diversos fatores, como a "rápida disponibilização; alcance a um público mais amplo e diversificação; redução de custos tanto na publicação quanto na distribuição; contribuição à natureza, graças à diminuição do consumo de papel" (Vanti, 2010, p. 200). Nesse sentido, ressalte-se que o IBICT tem incentivado, instrumentado e capacitado a criação de periódicos eletrônicos na plataforma tornada disponível pelo Public Knowledge Project (PKP), da University of British Columbia do Canadá, por meio do Open Journal Systems (OJS), customizado no Brasil como Sistema Eletrônico de Editoração de Revistas (SEER) (Costa, 2008; Vanti, 2010). O SEER permite o gerenciamento de todas as etapas do workflow de uma publicação científica e utiliza padrões de interoperabilidade da Iniciativa de Arquivos Abertos (Open Archives Initiative - OAI), podendo ser utilizado por qualquer instituição ou particular que se interesse em fundar e manter uma publicação eletrônica de acesso aberto Moreno, Leite, e Arellano (2006).

\section{Modelos de Escolas de Governo}

Para Pacheco (2000, 2003 apud (Ranzini \& Bryan, 2017), o conceito de Escola de Governo é bastante amplo, tem utilização imprecisa e vem sendo usado indistintamente por organizações públicas, privadas ou não-governamentais nas três esferas de governo na formação e aperfeiçoamento de seus quadros. Ranzini e Bryan (2017) analisaram diversas Escolas de Governo e sumarizam os modelos como a seguir:

a) Escolas de governo localizadas em ambiente governamental: são organizações vinculadas direta ou indiretamente ao aparato estatal, financiadas e/ou mantidas por recursos públicos;

b) Escolas de governo localizadas em ambiente governamental: são organizações vinculadas direta ou indiretamente ao aparato estatal, financiadas e/ou mantidas por recursos públicos; 
c) Universidades Corporativas: organizações com fins lucrativos, do setor público ou privado, para a capacitação profissional de servidores públicos;

d) Organizações não governamentais: organizações do setor privado com ou sem fins lucrativos que ofertam cursos voltados à temática pública para diversas categorias de agentes públicos, políticos e cidadãos, mesmo não estando vinculadas ao aparato estatal; e

e) Fundações partidárias: organizações do setor privado, sem fins lucrativos, vinculadas a partidos políticos, com o objetivo de promover a educação e formação política e cidadã para os militantes partidários e para a população de forma geral.

\section{Escolas de Governo dos Ministérios Públicos}

Para Almeida (2018, p. 37), o novo perfil constitucional do Ministério Público, tanto no âmbito da atuação jurisdicional quanto da atuação extrajurisdicional, "impõe à Instituição uma atuação prática que faça com que sua legitimação social não decorra somente da Constituição, mas acima de tudo do seu trabalho na proteção e na efetivação dos direitos fundamentais". O autor cita, dentre outros fatores de legitimação social do Ministério Público, o exercício da função pedagógica da cidadania e a formação humanista, multidisciplinar e interdisciplinar de seus membros e servidores.

Como o acesso à informação e ao conhecimento promovem inovação social, de forma conjunta com a promoção do desenvolvimento local e da inclusão social (Albagli, 2006 apud (Bertin et al., 2009), o Ministério Público deve se adequar às novas exigências da economia do conhecimento, para não refletir padrões hegemônicos de produção, apropriação e disseminação do conhecimento em seus processos de produção e de serviços.

No presente artigo, optou-se por analisar as Escolas dos Ministérios Públicos, conforme relação de Escolas que integra o CDEMP Essas Escolas são disciplinadas em âmbito federal pelo artigo 35 da Lei Orgânica Nacional do Ministério Público, Lei no . 8.625, de 12 de fevereiro de 1993 (2003)e em âmbito estadual, quando cabível, por suas respectivas Legislações Complementares estaduais. Segundo Brasil (2018), as Escolas Institucionais também possuem a função estratégica de inteligência institucional e seu escopo estratégico de atuação não se limita ao alinhamento e consecução do planejamento estratégico, das políticas de gestão do respectivo Ministério Público, mas também se vincula à estratégia nacional da Instituição, como definido de forma plural nos órgãos setoriais colegiados como o CDEMP e o CNMP.

Nos Ministérios Públicos, é possível encontrar o modelo de Escolas de Governo financiadas e/ou mantidas por recursos públicos dos Ministérios Públicos dos Estados e da União. Essas Escolas são muitas vezes denominadas "Centro de Estudos e Aperfeiçoamento Funcional" (CEAF) (Brasil, 2018). Como esses modelos de escola integram a estrutura dos órgãos dos Ministérios Públicos, são denominadas Escolas Institucionais (Goulart et al., 2017). Existe ainda no âmbito das Escolas dos Ministérios Públicos vinculadas ao CDEMP o modelo de organizações não governamentais, na forma de fundações de direito privado sem fins lucrativos e ligadas às Associações de classe do Ministério Público ou escolas fundacionais, normalmente denominadas Fundação Escola (Superior) do Ministério Público (Brasil, 2018; Goulart et al., 2017).

Em alguns estados, as escolas fundacionais e/ou as escolas associativas podem coexistir com os CEAFs ou representar a única alternativa de modelo de Escola de Governo. Nos estados em que esses diversos modelos coexistem, normalmente, segundo Goulart et al. (2017, p. 48-49) existe uma divisão de tarefas, em que os CEAFs "promovem, prioritariamente, o aperfeiçoamento funcional dos agentes políticos e administrativos dos quadros do Ministério Público", e as escolas associativas ou fundacionais "responsabilizam-se pelos cursos de pós-graduação e de preparação de futuros quadros" de membros dos Ministérios Públicos, isto é, oferecem cursos preparatórios para concursos. Já em São Paulo, segundo os autores, o CEAF cumpre com exclusividade todas as tarefas de formação e capacitação para os públicos interno e externo (Goulart et al., 2017) e que passou a ser denominado Escola Superior do Ministério Público de São Paulo desde 1998.

Para Goulart (2017)), quanto à dimensão político-institucional, as Escolas Institucionais dos Ministérios Públicos se diferenciam de unidades comuns de capacitação de pessoal, em razão de desempenharem atividades de maior complexidade, pois, além de promoverem, em alguns estados, cursos de pós-graduação até em nível stricto sensu, devem desenvolver estudos, pesquisas e projetos voltados à melhoria institucional. As Escolas Institucionais de Ministério Público integram o sistema público de ensino, na modalidade Educação Profissional, conforme o art. 39, caput, da Lei de Diretrizes e Bases da Educação Nacional, Lei no. 9.394, de 20 de dezembro de 1996 (1996), e regem-se por pelos princípios de (a) autonomia pedagógica (liberdade de aprender, ensinar, pesquisar e divulgar o pensamento, a arte e o saber); (b) gestão democrática do ensino; (c) acesso universalizado do público-alvo prioritário; (d) gratuidade do ensino público; (e) garantia do padrão de qualidade; (f) pluralismo de ideias e de concepções pedagógicas (Goulart, 2017). 


\section{METODOLOGIA}

A abordagem utilizada na pesquisa é a abordagem de natureza qualitativa. O presente estudo pautou-se por ser um estudo exploratório, pois teve como objetivo primordial aprofundar o conhecimento sobre a frequência da ocorrência de periódicos de acesso livre e de repositórios abertos nas Escolas de Governo dos Ministérios Públicos no Brasil. Segundo (Diehl \& Tatim, 2004, p.53), a pesquisa exploratória "tem como objetivo proporcionar maior familiaridade com o problema, com vistas a torná-lo mais explícito ou a construir hipóteses". Sobre a pesquisa exploratória, Gil (2016) acrescenta que esse tipo de pesquisa apresenta menor rigidez no planejamento, pois objetiva proporcionar visão geral acerca de determinado fato. Gil (2016, p. 27) considera que a pesquisa exploratória tem como "principal finalidade desenvolver, esclarecer e modificar conceitos e ideias, tendo em vista a formulação de problemas mais precisos ou hipóteses pesquisáveis para estudos posteriores".

Em relação ao procedimento técnico da coleta de dados, a pesquisa adotou as técnicas de pesquisa documental. Optou-se pela realização de coleta de dados por meio de pesquisa bibliográfica e documental. Segundo Diehl e Tatim (2004),

[A pesquisa documental] assemelha-se à pesquisa bibliográfica. A diferença fundamental entre ambas é a natureza das fontes. Enquanto a pesquisa bibliográfica se utiliza fundamentalmente das contribuições de diversos autores sobre determinado assunto, a pesquisa documental vale-se de materiais que ainda não receberam tratamento analítico, ou que ainda podem ser reelaborados de acordo com o objetivo do trabalho. (Diehl \& Tatim, 2004, p. 59)

No presente artigo, a pesquisa documental consistiu de pesquisa em repositórios abertos e portais corporativos extranet das Escolas de Governo dos Ministérios Públicos no Brasil, conforme a indicação constante no sítio do CDEMP. Em alguns estados, há mais de uma Escola de Governo vinculada ao CDEMP, totalizando-se 37 escolas. Foram analisados somente periódicos de caráter científico, isto é, as revistas visando marketing institucional foram desconsideradas na contagem. As revistas periódicas impressas ou cujo conteúdo consistia de promoção institucional não foram contabilizadas.

Optou-se pelo tratamento dos dados por meio de tabulação simples, isto é, do agrupamento e contagem da frequência de ocorrência (Gil, 2016) ou não de revistas eletrônicas de acesso livre e de repositórios abertos no portal corporativo do CDEMP, nos portais corporativos extranet das Escolas de Governo dos Ministérios Públicos no Brasil. Os dados foram organizados por estado e por Escola de Governo e foi verificada nos portais corporativos a ocorrência ou não de repositórios institucionais e/ou de periódicos eletrônicos de acesso aberto. Após a contagem, foi realizado o cálculo do percentual de ocorrências (Marconi \& Lakatos, 2016)

\section{Análise dos resultados}

Os resultados indicam que, de um total de 37 Escolas de Governo vinculadas ao CDEMP, obteve-se que 21 (56,7\%) não possuíam periódico eletrônico, ante 16 (43,3\%) que editam seu periódico em formato eletrônico. Desses periódicos eletrônicos, cinco (13,5\%) utilizam o sistema de gerenciamento de periódicos SEER. Nos demais casos, os periódicos são gerenciados por sistemas próprios desenvolvidos pelo órgão respectivo.

Em relação à disponibilização pelas Escolas de Governo de repositório digital aberto, 22 (59,5\%) não possuíam repositório, ante $15(40,5 \%)$ com repositórios abertos em meio eletrônico. Dentre os repositórios, a maioria (13 86,7\%) disponibiliza livros e outras publicações de acesso aberto e destes, dois disponibilizam também vídeos de caráter pedagógico e dois disponibilizam acesso a bibliotecas digitais abertas. Os outros dois $(13,3 \%)$ repositórios disponibilizam somente artigos jurídicos, nas áreas de atuação do Ministério Público, sem indicação sobre seleção por meio de revisão por pares.

A diversificação de meios pelos quais a informação pode ser disseminada é importante no contexto dos repositórios. Assim, a utilização de vídeos, por exemplo, demonstra uma busca por diversidade de mecanismos de compartilhamento do conhecimento, permitindo que as informações cheguem a um número maior de usuários.

Tal resultado é uma indicação da busca pelas Escolas de Governo vinculadas ao Ministério Público por um modelo de divulgação de conhecimentos cuja base seja científica, permitindo a maior adequação das informações às finalidades institucionais do órgão. Com a redução de custos, maior visibilidade e grande velocidade na disseminação da informação permitida pelas publicações digitais (Vanti, 2010), o corpo técnico do órgão público, bem como os demais interessados, tem uma facilidade na busca por informações necessárias aos trabalhos realizados. A ausência de indicação sobre a forma de seleção dos artigos, daqueles artigos disponibilizados, pode gerar alguma desconfiança sobre a adequação científica ou qualidade do trabalho. Assim, a forma de seleção dos trabalhos incluídos nos repositórios deveria ser clara, permitindo a avaliação pelo usuário de sua adequação.

Ao se verificar conjuntamente a presença de periódicos eletrônicos livres e/ou repositórios digitais abertos nos portais extranet dessas Escolas de Governo, observou-se que dez (27\%) das escolas analisadas possuíam repositório e periódico; 16 (43,3\%) das escolas não possuíam repositório e nem periódico; cinco (13,5\%) das escolas possuíam somente repositório digital; e seis $(16,2 \%)$ das escolas possuíam somente periódico eletrônico. 
Ressalta-se que tais iniciativas, especialmente por serem provenientes de uma instituição pública cujo papel constitucional visa, precipuamente, a defesa de direitos fundamentais, permitem efetivar o direito à informação - e a própria necessidade de informação do Ministério Público. Apesar disso, ainda é baixa a transparência e divulgação científica das Escolas de Governo. Mais de $40 \%$ das Escolas não disponibilizam em suas extranets a possibilidade de acesso a periódicos ou repositórios.

Conforme Bertin et al. (2009) é impossível separar a divulgação de informação e inovação social. O Ministério Público, cumprindo seu mister, deve buscar a inovação por meio da utilização de mecanismos de divulgação científica - seja de forma interna, servindo aos fins primários da instituição, seja de forma externa, fornecendo à sociedade dados para a análise e permitindo a disseminação de sua produção.

\section{CONCLUSÕES FINAIS}

Como se percebeu dos resultados, o número de Escolas de Governo que não possuem instrumentos de disseminação de informação científica aberta ainda é alto, apesar da orientação de valorização das Escolas Institucionais expressa na Carta de Brasília, de 22 de setembro de 2016 (2016) e na Recomendação de Caráter Geral CN-CNMP n. ${ }^{2}$, de 4 de julho de 2017 (2017).

O desenvolvimento local e a inclusão social são fundamentalmente interligados à disseminação da informação científica como fator de inovação social (Bertin et al., 2009). Nesse contexto, as Escolas Institucionais, assim como as Escolas de Governo, não devem ser reduzidas a meros espaços de formação técnica, mas sim se devem estruturar como espaços de trocas sociais e culturais democráticas (Garcia \& Sales, 1999) e críticas das relações de poder subjacentes no acesso ao conhecimento.

Em resposta a um cenário de demandas crescentes e de restrições orçamentárias e, principalmente, ante um cenário de dificuldade de estruturação ideal das Escolas de Governo, sugere-se também a ampliação da atuação em rede por parte das Escolas dos Ministérios Públicos, principalmente entre aquelas que possuem o modelo de Escola Institucional. Essa articulação em rede ocorreria por meio da celebração de convênios, parcerias e protocolos de cooperação (Brasil, 2018) com outras Escolas de Governo, com universidades, faculdades, centros universitários e centros de pesquisa nacionais e estrangeiros, com o intuito de se compartilhar conhecimentos. Como órgãos estratégicos da política institucional, as Escolas de Governo do Ministério Público devem se instrumentalizar para que possam continuar a cumprir sua missão institucional em um ambiente de mudanças constantes e demandas crescentes.

O estudo demonstra a relevância de políticas institucionais que fortaleçam as Escolas dos Ministérios Públicos, principalmente aquelas Escolas Institucionais, cujas estruturas administrativas integram as Instituições. É importante que as Escolas adotem sistemas como o SEER, que permite o gerenciamento de todas as etapas do workflow de uma publicação científica, utiliza padrões de interoperabilidade da Iniciativa de Arquivos Abertos e é disponibilizado gratuitamente pelo IBICT. Esse modelo de publicação científica eletrônica permite alcançar um público amplo e diversificado, além de reduzir custos na publicação e, principalmente, na distribuição do periódico. O IBICT também disponibiliza as plataformas DSpace ou E-prints gratuitamente, com o ganho institucional de se utilizar uma ferramenta que pode auxiliar gestores em seus processos decisórios e planos estratégicos (Muller \& Oliveira, 2015) e permitir a recuperação da informação e a manutenção de uma memória documental.

Uma consideração a ser pontuada refere-se à efetividade da busca dos repositórios e revistas para tornar artigos acessíveis, uma vez que muitas vezes, as páginas não são amigáveis com os usuários, principalmente o público externo à Instituição. Apesar de essas revistas e repositórios existirem, eles não têm necessariamente fácil acesso, demandando uma busca mais detida nos sítios oficiais dos órgãos. Nesse contexto, tem-se que a disponibilidade representa a capacidade de mecanismos de busca em recuperar links de um documento, preferencialmente, dentre as duas primeiras páginas dos resultados, e a acessibilidade, como sendo o número de cliques requeridos por um usuário para navegar dos resultados até o texto do documento (Lee, Burnett, Baeg, Vandegrift, \& Morris, 2015). Essa realidade pode ser implementada no planejamento dos sítios corporativos, de maneira a se privilegiar a navegação dos usuários nos conteúdos das Escolas Institucionais. Por se tratarem de instituições privadas, as Escolas de Governo fundacionais e associativas podem também repensar a disponibilização de seus conteúdos, privilegiando o acesso aberto e gratuito a revistas acadêmicas, cujo objetivo final é obter alto grau de visibilidade e citação para os seus autores.

Por fim, o presente trabalho não se propôs a exaurir a questão do ponto de vista teórico ou metodológico e espera-se que possa servir como referencial para futuras pesquisas aplicadas, no contexto das Escolas de Governo. Em razão da heterogeneidade das regiões brasileiras e também dos modelos de Escolas de Governo pesquisadas, sugere-se a realização de futuros estudos de caso para a avaliação focalizada nas necessidades individuais de cada organização, além de estudos que foquem especialmente a efetividade da busca de repositórios e revistas quanto ao número de cliques para o acesso ao documento e quanto à capacidade de se recuperar links que estejam dentre os resultados constantes das primeiras páginas de mecanismos de busca. 


\section{REFERÊNCIAS}

Almeida, G. A. (2018). Métodos de ensino nas faculdades de direito dos estados unidos e a possibilidade de sua utilização nas escolas do ministério público brasileiro: reflexões a partir da experiência de pesquisa na faculdade de direito da universidade de syracuse. In 30 anos da constituição de 1988 e o ministério público: avanços, retrocessos e os novos desafios. Belo Horizonte: D'Plácido.

Arbix, G. (2010). Estratégias de inovação para o desenvolvimento. Tempo Social: Revista de Sociologia da USP, 22(2), 167-185. Recuperado de https://www.scielo.br/pdf/ ts/v22n2/v22n2a09.

Baumgarten, M. (2017). C\&t na semiperiferia e inovação social: desigualdades, excelência e competitividade. In Informação e desenvolvimento: conhecimento, inovação e apropriação social. (v. 1, p. 271-295). Brasísila: UNESCO.

Bertin, P. R. B., Leite, F. C. L., \& Pereira, F. A. (2009). A informação em ciência e tecnologia como insumo para a inovação social: elementos para discussão. In 23 anais do congresso brasileiro de biblioteconomia, documentação e ciência da informação. Bonito: Universidade do Porto. Recuperado de https://repositorio.unb.br/handle/10482/ 12143.

Bignetti, L. P. (2011). As inovações sociais: uma incursão por ideias, tendências e focos de pesquisa. Ciências Sociais Unisinos, 47(1), 03-14. doi: 10.4013/csu.2011.47.1.01.

Brasil, L. F. (2018). As escolas institucionais do ministério público e o seu papel na formação e aprimoramento funcional do ministério público. In 30 anos da constituição de 1988 e o ministério público: avanços, retrocessos e os novos desafios. Belo Horizonte: DPlácido.

Carbonell, J. (2002). A inovação educativa hoje. In J. Carbonell (Ed.), A aventura de inovar: a mudança na escola. Porto Alegre: Artmed.

Carta de Brasília, de 22 de setembro de 2016. (2016). Modernização do controle da atividade extrajurisdicional pelas corregedorias do ministério público. Diário Oficial da União. Recuperado de http://www.cnmp.mp.br/portal/ images/Carta_de_Bras\%C3\%Adlia-2.pdf.

Constituição da república federativa do brasil de 1988. (1988). Diário Oficial da União. Recuperado de http://www.planalto.gov.br/ccivil_03/constituicao/ constituicaocompilado.htm.

Costa. (2008). Abordagens, estratégias e ferramentas para o acesso aberto via periódicos e repositórios institucionais em instituições acadêmicas brasileiras. Liinc em Revista, 4(2), 218-232. doi: 10.18617/liinc.v4i2.281.

Costa, \& Valente. (2015). O repositório de conteúdo digital nas pesquisas de história da educação matemática. Revista Iberoamericana do Patrimônio Histórico-Educativo, 1(1), 96-110. doi: 10.20888/ridphe r.v1i1.9231.

Dagnino, R., Brandão, F. C., \& Novaes, H. T. (2004). Sobre o marco analítico-conceitual da tecnologia social. In Tecnologia social: uma estratégia para o desenvolvimento. Rio de Janeiro: Fundação Banco do Brasil.

Declaração de berlin sobre o acesso aberto ao conhecimento em ciê ncia e humanidade. (2003). Recuperado de http://www.zim.mpg.de/openaccess-berlin/ berlindeclaration.html.

Declaração de budapeste. (2002). Recuperado de http:// www.soros.org/openaccess.
Declaração de salamanca e linha de ação sobre necessidades educativas especiais. (1994). Coordenadoria para Integração da Pessoa Portadora de Deficiência. Recuperado de http:// portal.mec.gov.br/seesp/arquivos/pdf/salamanca.pdf

Decreto $n^{\circ}$ 5.707, de 23 de fevereiro de 2006. (2006). Diário Oficial da União. Recuperado de http://www.planalto.gov .br/ccivil_03/_ato2004-2006/2006/decreto/d5707.htm.

Diehl, A. A., \& Tatim, D. C. (2004). Pesquisa em ciências sociais aplicadas: métodos e técnicas. São Paulo: Prentice Hall.

Diogo, V., \& Guerra, P. (2003). Inovação social como utopia renovada: o caso da associação humanitária habita. Sociologia: Revista da Faculdade de Letras da Universidade do Porto, 25, 141-163. Recuperado de http://www.scielo .mec.pt/pdf/soc/v25/v25a08.pdf.

Garcia, M. V., \& Sales, R. (1999). O papel da escola de governo na construção de uma nova relação entre estado e terceiro setor: da desconfiança à parceria. Revista Paranaense de Desenvolvimento, 96(3), 77-89. Recuperado de http:// www.ipardes.gov.br/pdf/revista_PR/96/vileni.pdf.

Gil, A. C. (2016). Métodos e técnicas de pesquisa social. (6a. ed.). São Paulo: Atlas.

Goulart, M. P. (2017). Órgãos de execução, escolas institucionais e corregedorias na dinâmica do ministério público. Revista Jurídica: Corregedoria Nacional, 2, 29-49. Recuperado de http://www.esmp.sp.gov.br/revista_esmp/ index.php/RJESMPSP/article/view/273.

Goulart, M. P., Arantes, P. H. O., Tostes, E., Andrade, J. S., Guimarães, D. S. A., Andrade Júnior, J. R. P., .. Jesuíno, S. A. B. (2017). O centro de estudos e aperfeiçoamento funcional na sistemática do ministério público contemporâneo. Revista Jurídica da Escola Superior do Ministério Público de São Paulo.(7), 45-48. Recuperado de http://www.cnmp.mp.br/portal/publicacoes/250 -revistas/10135-revista-juridica-corregedoria-nacional-2017.

Guédon, J. C. (2010). Acesso aberto e divisão entre ciência predominante e ciência periférica. In Acessibilidade e visibilidade de revistas científicas eletrônicas. (p. 19-42). Sào Paulo: Editora SENAC, Cengage Learning.

Guimarães, M. C. S., Silva, C. H., \& Borges, M. M. (2015). Via dourada no brasil e em portugal: uma década depois de budapeste. In Vii encuentro ibérico edicic 2015. Madrid: Universidad Complutense de Madrid. Recuperado de http:// hdl.handle.net/10316/29970.

Lacerda, L. F. B., \& Ferrarini, A. V. (2013). Inovação social ou compensação? reflexões acerca das práticas corporativas. Polis(35), 01-20. Recuperado de http://polis.revues.org/ 9108.

Lee, J., Burnett, G., Baeg, J. H., Vandegrift, M., \& Morris, R. J. (2015). Availability and accessibility in an open access institutional repository: A case study. Information Research, 20(1), 334-349. Recuperado de http://diginole.lib.fsu.edu/ islandora/object/fsu:252681/datastream/PDF/view.

Lei $n^{\circ}$. 12.527, de 18 de novembro de 2011. (2011). Diário Oficial da União. Recuperado de http://www.planalto.gov .br/ccivil_03/_ato2011-2014/2011/lei/112527.htm.

Lei $n^{\circ}$. 8.625, de 12 de fevereiro de 1993. (2003). Diário Oficial da União. Recuperado de http://www.planalto.gov .br/ccivil_03/leis/L8625.htm.

Lei $n^{\circ}$. 9.394, de 20 de dezembro de 1996. (1996). Diário Oficial da União. Recuperado de http://www.planalto.gov .br/ccivil_03/LEIS/L9394.htm. 
Marconi, M. A., \& Lakatos, E. M. (2016). Técnicas de pesquisa: planejamento e execução de pesquisa, elaboração, análise e interpretação de dados. (7a. ed.). São Paulo: Atlas.

Moreno, F. P., Leite, F. C. L., \& Arellano, M. A. M. (2006). Acesso livre a publicações e repositórios digitais em ciência da informação no brasil. Perspectivas em Ciências da Informação, 11(1), 82-94. doi: https://www.scielo.br/pdf/pci/v11n1/v11n1a07.pdf.

Mueller, S. P. M. (2006). A comunicação científica e o movimento de acesso livre ao conhecimento. Ciéncia da Informação, 35(2), 27-38. Recuperado de http://revista .ibict.br/ciinf/article/view/1138.

Muller, C. C., \& Oliveira, K. S. (2015). Repositório institucional da enap: um processo de construção coletiva do conhecimento. Cadernos Eneap, 41, 01-111. Recuperado de http://repositorio.enap.gov.br/handle/1/2203.

Ranzini, M. S., \& Bryan, N. A. P. (2014). Portaria $n^{\circ}$ 86, de 13 de junho de 2014. institui regulamento da revista do serviço público, inclusive estrutura editorial e normas de submissão editorial. Boletim Interno da ENAP(Edição Extraordinária 1). Recuperado de http://repositorio.enap .gov.br/1/1197.

Ranzini, M. S., \& Bryan, N. A. P. (2017). Capacitação e formação para o setor público e os modelos de escola de governo no brasil. Revista do Serviço Público, 68(2), 417-438. doi: 10.21874/rsp.v68i2.1004.

Recomendação de caráter geral cn-cnmp n. ${ }^{\circ}$ 2, de 4 de julho de 2017. (2017). Diário Oficial da União. Recuperado de http://www.cnmp.mp.br/portal/images/Recomenda\% C3\%A7\%C3\%A3o_n._02.pdf

Sayão, L. F., \& Sales, L. F. (2014). Dados abertos de pesquisa: ampliando o conceito de acesso livre. RECIIS: Revista Eletrônica de Comunicação, Informação, Inovação em Saúde, 8(2), 76-92. doi: 10.3395/reciis.v8i2.611.

Shintaku, M., \& Vidotti, S. A. B. G. (2016). Bibliotecas e repositórios no processo de publicação digital. Biblos: Revista do Instituto de Ciéncias Humanas e da Informação, 30(1), 61-80. Recuperado de https://periodicos.furg.br/ biblos/article/view/5762/3993.

Vanti, N. (2010). Indicadores web e sua aplicação à produção científica disponibilizada em revistas eletrônicas. In Acessibilidade e visibilidade de revistas científicas eletrônicas. (p. 271-295). São Paulo: Editora SENAC, Cengage Learning.

Como citar este artigo (APA):

Santos, A. de S. \& Figueiredo, F. C. (2020). A disseminação de informação científica em escolas de governo como fator de inovação social. AtoZ: novas práticas em informação e conhecimento, 9(1), 85 - 93. Recuperado de: http://dx.doi.org/10.5380/atoz.v9i1.64675 